\title{
Institutional Design for Biodiversity Conservation
}

\author{
Harry Clarke
}

$\mathrm{I}$ $\mathrm{n}$ this paper we examine when it is that private institutions can be relied on to conserve biodiversity and when, alternatively, public institutions are preferable. Circumstances are also described where regulated private provision or 'club good' institutions are appropriate and where public biodiversity resources should be corporatised by employing private managers who respond to commercial incentives subject to regulation.

Institutional choices partly determine incentives to conserve. Property-right arrangements are an important facet of institutional design. Private property results when residual claimant rights to the use of biodiversity property reside with private individuals. If residual claimant rights accrue to the public sector, the property is public. On public land, a further aspect of institutional design concerns how managers are encouraged to respond to commercial incentives.

Biodiversity measures the 'variety of life'. Specific biological definitions focus on genetic, population, species or ecosystem diversities. For the most part this paper concentrates on species biodiversity. The general concept of biodiversity reflects a wide set of natural resource attributes whose relative importance is subject to disagreement and uncertainty at any given time, and for which social valuations are likely to change through time. Land will have various plant and animal populations living on it and is subject to more-or-less passive use by biodiversity observers and other recreational users. Land also provides existence, option and other non-use values. Thus an important component of biodiversity consumption involves individuals passively observing biodiversity or realising non-use values from knowing that biodiversity is conserved. The production of biodiversity refers to those costly resource uses that assist in biodiversity preservation or prevent its decline. Land can also be used commercially for production or urban use. In this paper activities producing biodiversity benefits are defined to be conservation while activities providing alternative products are other production. Both dedicated conservation provision (for example, pristine forests with wildlife) and the dedicated provision of 'other production' are a priori possible. So, too, are mixed systems where biodiversity is protected on private agricultural or urban land.

There are several reasons for pursuing conservation on private as well as public land.

- Much land is privately owned or subject to leasehold contract. In Australia 60 per cent of land is private (Aretino et al., 2001). Often this land is 
biodiversity rich or provides crucial habitat or relic populations. Given complementarities between biodiversity and the production and consumption of other outputs, the delivery of 'other production' need not entirely exclude conservation outputs.

- Public land for conserving biodiversity occupies large areas and is subject to high aggregate management costs. These costs limit the pursuit of conservation by the public sector. In some cases if land can be jointly used for conservation and other commercial uses, conservation objectives can be advanced at lower cost than would occur with specialised pursuit of biodiversity conservation alone.

- Conservation demands grow relative to GDP as society becomes wealthier if, as is supposed here, the environment is a luxury good. (This is plausible folklore and is provisionally accepted but note that Kriström and Riera (1996) provide evidence that the environment is a normal, non-luxury good).

- The intensity of conservation effort has increased over recent years as conservation biology shifts from typological to populational perspectives: conservation biologists point out that sub-species and population-based differentiations drive natural selection so they urge targeting of sub-species and local populations rather than species per se: see Meffe et al. (1997:6768). The main scope for such increased effort is on private rather than public land partly because limits to public land supplies have often been irreversibly established. In Australia the National Strategy for the Conservation of Australia's Biodiversity (Environment Australia, 2001) recognises a need to encourage conservation on private land as a key component of national conservation efforts.

Private landowners will often undertake conservation effort partly because of public regulations and incentives to conserve and partly because of their own conservationist values. In addition, there are reasons for seeking private involvement in managing biodiversity on public land using incentive contracts. Motivated by contracts that give them part of any increased return they realise from biodiversity management, private managers on public land may be motivated to:

- Achieve cost economies. For example, by improving labour management, making more disciplined use of capital, communications and road improvements and making more focused conservation efforts. In some cases pursuit of biodiversity goals can be integrated with generating 'other production', yielding cost efficiencies.

- Introduce innovatory practices into biodiversity management. Examples of such practices include the control of feral intruders, the use of improved fencing or the marketing of biodiversity to facilitate ecotourism. Finally, managers may be motivated to provide complementary consumables (camp 
sites, board walks in wetlands and so on) to enhance provision of recreational use values.

Contracts that realise these objectives without unsought adverse effects are not simple to write. A key issue is ignorance of biodiversity production functions by both public and private managers. This acts as a barrier to writing mutually acceptable and enforceable contracts. In addition, there are information asymmetries in managing biodiversity that create moral hazard by managers. In particular, inappropriate cost cutting and the inappropriate provision of environmentally damaging complementary consumables can detract from the quality of conservation outcomes. These difficulties can limit the scope for using private incentives.

These concerns are addressed in this paper. In the next section unregulated private provision of biodiversity is examined. The key requirement for this structure to work well is that there exist nonattenuated property rights on biodiversity. Rivalry is not a necessary prerequisite for private provision if 'club goods' structures can be utilised and if there are motives for governments to foster such structures. Nor do externalities destroy the possibilities for private provision if such externalities can be addressed with corrective economic instruments. In the following section the alternative, extreme public provision institution is examined. This can be an optimal management structure when property rights are attenuated. The paper examines how such public biodiversity resources should be managed and, in particular, whether traditional public managers or corporatised management structures using incentive contracts should be used. This choice depends on moral hazard, whether non-contractible cost reductions reduce quality, and on the importance of innovation in management. The last section summarises the conclusions.

\section{Private Biodiversity Supplies}

The motive for private ownership is to reduce conservation costs and to improve conservation outcomes by creating incentives for innovation. Private owners have incentives to cost-cut and to pursue innovatory practices since, with appropriate contracts, they reap rewards from these efforts. Such incentives work provided competitive imperfections such as monopoly power and scale economies do not arise (we here assume the absence of these difficulties) and provided nonattenuated property rights prevail. Nonattenuated property rights are:

- Complete. Property rights on biodiversity (and other production) must be fully specified with ownership defined without uncertainty at negligible contracting cost.

- Exclusive. Rewards and penalties resulting from buying or selling biodiversity (or other production) must accrue directly to resource owners.

- Transferable. Property rights on all resources must gravitate by free exchange to their highest-valued use with negligible transactions costs. 
- Enforceable. Property rights must be completely enforced at negligible policing cost.

In our analysis of the case for private ownership a distinction between dedicated and mixed modes of biodiversity provision is highlighted because biodiversity conservation is sometimes seen as necessarily substituting for production or consumption of other goods. Given property rights, whether biodiversity production should completely displace the production of other goods depends on the marginal rate of transformation between biodiversity and the other goods. Whether biodiversity substitutes for consumption of other goods depends, in turn, on marginal rates of substitution in consumption between outputs. Moreover, with strict complementarities in consumption (or production), even should conservation be a substitute for production (respectively, consumption) of other goods it will be socially desirable to diversify by providing a mix of biodiversity and other outputs.

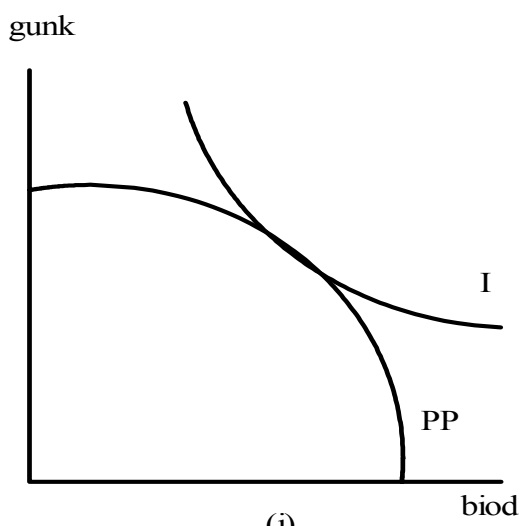

(i)

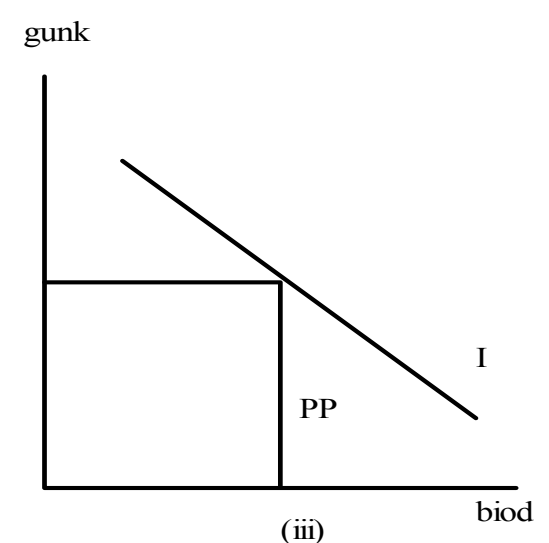

(iii)

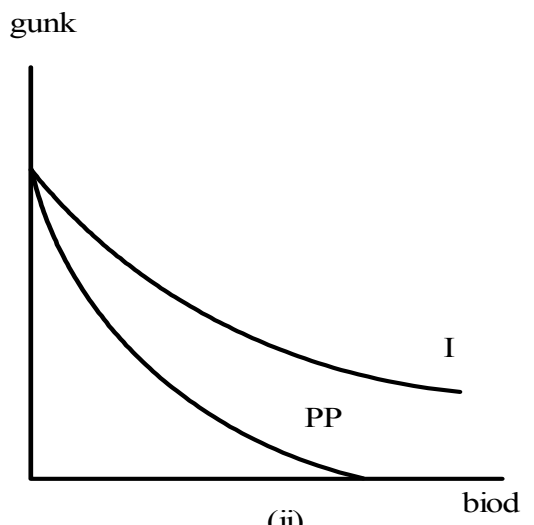

(ii)

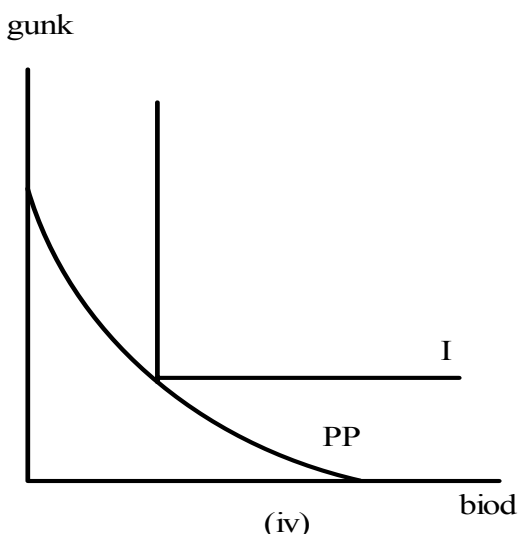

(iv)

Figure 1 
Figure 1 describes four versions of a single consumer, single firm economy that uses land to produce 'other production' (gunk) and biodiversity (biod). Indifference curves I describe consumer preferences while PP shows transformation curve possibilities between outputs. Non-attenuated property rights are assumed and private producers are assumed to be well-informed about gunk and biodiversity production processes. In case (i) I are convex and PP concave so that joint production of both gunk and biodiversity (defined by the common tangency of PP and I) is socially efficient. Achievement of this equilibrium can be decentralised using competitive markets where producers rely on profit signals and consumers maximise utility. Case (ii) shows that, with certain concave I and concave PP (due, for example, to economies of scale in either type of production), efficiency can call for zero biodiversity production. While alternative concave tastes and convex technologies are consistent with interior biodiversity and other outputs, such equilibria, even if they arise, are not achievable in decentralised markets: planning is essential. Case (iii) shows that lack of consumption complementarity can be offset by strong enough production complementarities. Case (iv) illustrates a case where lack of production complementarity (no 'jointness') is offset by consumption complementarity. Equilibria in cases (iii) and (iv) are achievable using market incentives.

Thus with nonattenuated property rights, the social optimality of mixed provision of biodiversity and other production is efficient because of complementarities between either the production or consumption of biodiversity and other goods. Joint provision is likely to be inefficient only if biodiversity and gunk are both production and consumption substitutes.

Evidence of complementarity between biodiversity consumption and other goods is seen in consumer demands for ecotourism, gardening, pet keeping and generally in what are strong community desires for conserved biodiversity. Wilson (1984) argues humans experience biophilia, a genetically-based need for exposure to life and lifelike processes. Others see such arguments as romantically idealising nature with Henry (1974), for example, recognising a 'Japanese engineering and planning' view of the world where conditioning switches preferences away from any need for nature. Generally the claims concerning production complementarities between biodiversity and other goods lie at the heart of conservation debates. The 'green lobby', and indeed broader political constituencies, see biodiversity conservation as essential for sustainable development. Thus in agriculture, biodiversity delivers pollination, waste recycling, nitrogen fixation and even, according to the Gaia hypothesis in Lovelock (1988), homeostatic equilibrium services. At the practical level, the conservation of biodiversity attributes such as tree cover, insectivorous birds, water and soil quality are increasingly seen as important issues. Again, some see claimed production complementarities as green romanticism. But even if it is doubtful whether a particular species loss, such as a bird species, destabilises an ecosystem, if all insectivorous bird species are extinguished then insect attack may become more common causing degradation and instability. 
With production or consumption complementarities, joint provision of biodiversity and other goods is efficient with supplies reflecting social valuations of outputs. Moreover, with non-attenuated property rights, these social valuations are reflected in market prices.

\section{Marketability of biodiversity}

The above analysis assumes that property rights are non-attenuated. With complete and exclusive property rights, biodiversity is conserved by markets given plausible assumptions on complementarities in tastes and technologies. Clearly, however, the conditions under which property rights are non-attenuated are restrictive.

Completeness and exclusivity require that biodiversity be traded in markets. This is typically not so for endangered biodiversity subject to conservation effort. Trade in endangered species is usually illegal. In Australia, domestic sales for commercial reasons are prohibited with restrictions on exporting most native flora and fauna under the Wildlife Protection (Regulation of Exports and Imports) Act 1982. Some wildlife (kangaroos, brushtail possums, muttonbirds, wildflowers) is commercially exploited and some (crocodiles, clams, fish, prawns, crayfish) is captive bred or ranched for profit (Industry Commission, 1998:chapter 15) but these examples are a minor part of aggregate biodiversity and the species cited are generally so abundant they do not need to be subject to additional focused conservation effort ${ }^{1}$.

The case for legitimising trade in biodiversity reflects the view that, by valuing biodiversity, landowners have improved incentives to conserve it. Such incentives work when biodiversity has a high use relative to non-use value. This is so if harvested species provide marketable protein, if wildflowers provide a usable input in home decoration, or if charismatic flora and fauna have in situ or ex situ ecotourism values. Then, ignoring 'animal rights' and other objections to exploiting use values, commercialisation policies in these cases remove a prohibition on trade that allows markets to work. Such policies do not ensure nonextinction, however. Indeed, if the discount rate is high relative to a population stock's growth rate at low stock levels, and harvest costs at low stock levels are not excessively great, then extinction can promote economic efficiency: see Clark (1976). This is significant problem if external costs arise because of extinction.

Most conservation objectives however do not mainly involve pursuit of use value. Rather, there is pursuit of non-use values (existence, option values) for which property rights are non-enforceable because excludability does not obtain. An example might be the conservation of non-charismatic flora and fauna. Legalising trade in charismatic flora and fauna realises at best only easily achieved conservation objectives. In addition, with respect to endangered species, Clarke

1 A referee points out that this statement must be qualified with respect to crocodiles. Both salt and freshwater crocodiles were hunted in the post-war period to one per cent of their original levels. Commercial harvesting of species encouraged landowners to sustain crocodile habitat and this became part of the conservation effort. 
(2000a) shows 'second best' issues limit possible gains from trade. Permitting trade in captive bred species can produce poor conservation outcomes if there are high costs of preventing species poaching in nature.

\section{Externalities and nonrivalry}

The case for using private property institutions for conservation is not limited by the presence of externalities or consumption nonrivalry. Externalities can be corrected by economic instruments (Pigovian taxes or subsidies) funded from the public purse. Providing a full subsidy to biodiversity suppliers supplying unpaid for social benefits enables markets to deliver efficiency, while schemes seeking economies by paying less than the full social value of biodiversity promote inefficiency. Full subsidies can reflect merit good and intergenerational objectives. Merit good arguments can be motivated by supposing policymakers make the judgment that the community undervalues or is incapable of valuing biodiversity.

Indeed, even non-price tools can surrogate for economic incentives if: (i) there are high costs of monitoring inappropriate biodiversity use; (ii) optimal 'other' production is close to zero so a ban is appropriate; and (iii) if emergencies arise where uncertainty about costs and benefits cannot be resolved in time to avert major losses of benefits.

Nor is consumption nonrivalry an inevitable difficulty given excludability. This is important since observing biodiversity as part of an amenity consumption experience is a nonrival activity. When demand is high, congestion and environmental damage arise from use but, short of this, pursuit of non-use values, such as observing wild species, is nonrival. Efficient provision with nonrivalry then requires zero pricing of any 'observation' since marginal costs are zero. Private firms will underallocate land to such activities so that biodiversity is then underprovided. This motivates a standard case for public provision based on market failure. Optimal provision equates accumulated marginal valuations of biodiversity with marginal costs of foregoing other production - the BowenLindahl-Samuelson rule (Laffont, 1988:37; Clarke, 2003).

Alternatively, however, biodiversity can be delivered as a privately (or publicly)-provided club good - Sandler and Tschirhart (1980) provide a discussion of club goods. Those deriving marginal benefits from biodiversity subscribe an amount sufficient to purchase targeted conservation assets outright and then supply it among themselves as a club good at zero observation cost. The purchase will be made if the discounted consumer surplus accruing to members with purchase, which determines their willingness-to-pay, exceeds the resource cost. Since private interests can operate such clubs, public management is not an inevitable consequence of nonrivalry. Four comments on club good solutions are appropriate:

- User pays arguments favour such schemes over public provision since those deriving benefits pay for them. This is the benefits principle of public finance. 
- Hobbyists with willingness-to-pay for a stake in a 'biodiversity club' often have specialised conservation knowledge from which they derive utility. Fostering clubs can facilitate effective management at low community cost.

- Efficient club good solutions are consistent with external conservation benefits. Externalities can be addressed by subsidising capital or ongoing management costs. In Australia, such subsidies might be Natural Heritage Trust Grants.

- With ongoing costs of management or congestion costs, as there should be in an efficient club, there should be both usage-specific and fixed membership fees. If land purchasers seek to minimise their costs subject to meeting certain specific conservation and non-congestion objectives they will typically trade off these attributes against each other. This implies an optimal, non-zero, congestion level.

There are several examples of 'club good' structures in Australia. Dryland nature reserves such as Gluepot and Newhaven Stations, owned by the ornithological group Birds Australia, are private club goods. They offer the option of a fixed membership fee that, upon payment, provide unlimited access rights to observing rare dryland birds in the reserves. Earth Sanctuaries Ltd is a private firm attempting to conserve biodiversity (mainly mammals) with some of the character of a club good. It provides investors with negligible dividend returns but provides non-pecuniary returns to those with conservation interests. For information about ESL see their Annual Report 1999, Earth Sanctuaries Limited (1999) and Productivity Commission (2001). ESL has a club good character at least in the sense that a 20 per cent discount is offered to shareholders who consume its services. The Western Treatment Plant at Werribee in Melbourne is a public club good. It provides access to birdwatchers for a biannual fee of $\$ 70$ and thereafter entry is free. Zoos such as the publicly-owned Melbourne Zoo are also public club goods. Zoo ${ }^{2}$ users are offered the options of annual membership or a fixed entry fee. Users then may wish to visit only once or very occasionally. A fixed fee leaves the club good structure intact with low-interest members given a self selected price discrimination option at a lower membership fee.

\section{Public Biodiversity Supplies}

Arguments for public provision are traditionally rationalised in terms of lack of property right completeness due to imperfect information or to consumption nonexcludability. These attributes make it difficult for conservation agencies to regulate private institutions effectively, so as to advance social conservation objectives.

2 Zoos are becoming increasingly important in global conservation of rare animals. It is thought that about 800 species of mammal, 800 species of birds and 400 species of reptiles would disappear if there were no captive breeding programs of the type operating in zoos (Spellerberg and Hardes, 1992:52-56). 
Non-Excludability. Strict non-excludability, or high costs of enforcing excludability, are a motive for public provision of biodiversity. The consumption of much biodiversity is non-excludable because, in aggregate, it is prohibitively expensive to restrict access to the large areas of land necessary to conserve the wide variety of biota existing in nature. To compound such difficulties, while flora is sedentary much fauna is locally or even internationally migratory which increases problems of limiting access (Clarke, 1999; 2000b). Non-excludability means private markets under provide socially desired biodiversity conservation.

Moreover, as mentioned, partial enforcement of access rights that provides local excludability may be counterproductive for 'second best' reasons. Restricting access to biodiversity by fencing and charging entry fees becomes nonviable if neighbouring areas, having the same biodiversity values, are consumed as open access resources. Suppose, for example, that fire risk can damage biodiversity that is subject to inevitably unregulated access. It may then be preferable to provide free access to regulated, supervised biodiversity conservation sites if pricing to reflect fire risks on these sites provides incentives for more damaging, unregulated illegal access elsewhere ${ }^{3}$. Socially optimal access regimes have an 'all or nothing' character. The incentives are to either promote excludability on all such resources or to do it on none. The difficulty is to promote excludability on all resources without inducing large enforcement and monitoring costs.

Viability of private conservation operations can be enhanced if there are substantial transport costs of accessing competing open access resources or if managed resources involve provision of goods complementary to biodiversity (camp sites, food, accommodation, reduced search or access costs of viewing flora or fauna). Of course provision of such complementary goods may reduce the authenticity of a biodiversity consumption experience.

Efficient public biodiversity supplies are defined, as before, by the BowenLindahl-Samuelson 'public goods' rule. However, this rule is difficult to implement for particular candidate conservation projects, such as those dedicated to conserving particular species, if community knowledge of biodiversity values is low or misinformed. More plausibly, communities will have general preferences for biodiversity conservation that are revealed at the ballot box. These preferences drive tax-financed public expenditure on conservation that are allocated by politicians who reflect on the public appeal of such projects and the views of scientists with specialised knowledge of conservation needs. This can be an informed equilibrium that reflects scientific knowledge of conservation needs and also reflects conservation preferences.

3 It might be argued that access to selected sites could be priced and then hefty legal penalties imposed on illegal access to other sites. This works if policing and enforcement costs are low. These costs can be made arbitrarily low by making penalties for infringement high enough although there are well-known 'marginal deterrence' arguments against very high penalties. In addition, since biodiversity resources have often been accessed at low (or zero) costs in the past, draconian penalties on illegal access now are unlikely to receive community support: see Clarke et. al. (1993), Clarke (1997). 
Incompleteness. Completeness of property rights requires that information about ownership of biodiversity be perfect and shared by all. This is seldom the case for endangered biodiversity resources subject to conservation effort. The definition and distribution of such biodiversity is usually uncertain and provisional. Moreover, the knowledge of biodiversity that does exist and of appropriate conservation effort is asymmetrically distributed between biodiversity managers and conservation planners creating potential agency issues.

Public good issues and property right incompleteness provide a case against private provision in the absence of feasible regulations or contracts to deal with such problems. If regulations or contracts can be designed which ensure socially desired provision then private provision remains possible. Then landowners can carry out conservation or other activities and secure a return that reflects their ability to realise the social objectives that are embodied in regulations or contracts. Our immediate concern is to question the feasibility of such regulations or contracts.

Regulations and Contracting. A rationale for public provision of biodiversity stems from difficulties of designing regulations and contracts that drive sound conservation outcomes. Biodiversity is difficult to even define let alone to incorporate into a regulation or contract: indeed Gaston (1996:1) characterises biodiversity as a pseudocognate term since different users of this concept often have distinct views of what it means but act as if others shared their individual view. There are moral hazard difficulties of using private self interest to advance biodiversity objectives if policy authorities, on the one hand, and landowners or project managers, on the other, hold divergent objectives or have different information.

When might the public sector outperform regulated private firms in advancing biodiversity objectives given contracting difficulties? There are three aspects to this question: (i) defining and valuing biodiversity, (ii) coordination issues and (iii) quality contractibility issues. These are now discussed in turn.

\section{Contracts and the identification and valuation of biodiversity}

If there is no difficulty in identifying and valuing biodiversity, then design of conservation regulations on private land and design of incentive contracts for managing public biodiversity involves, in the main, specifying such identifications and valuations. Resources with very high conservation value will have their exploitation restricted by regulation or by contract. With respect to conservation on private land, given such identifications and valuations, biodiversity property rights will be allocated by one of two possible efficient Coasian assignments. Property rights can be assigned to society with landowners then charged the price of utilising biodiversity. Alternatively, property rights can be assigned to landowners with society compensating landowners for not using the biodiversity whose conservation is sought. 
By the Coase theorem, each of these latter assignments is efficient ${ }^{4}$. Which property right allocation should be made? If most amenity values provided by conservation accrue to society as a whole at a private cost to the landowner then the user-pays principle (or benefits principle of public finance) suggests assigning rights to the landowner. This sometimes also reflects historical circumstance and popular perceptions of where rights lie.

The alternative assignment of rights to society as a whole offers lower, realpolitic chances of realisation. This view ignores uncertainty in identifying and valuing conservation assets. These valuations will be stochastic and evolving through time: see Clarke \& Reed (1990). Moreover, the viability of conservation endeavours and the quality of conservation outcomes depend on managerial effort. Making high effort is costly in terms of work disutility but low effort is socially costly in terms of foregone production. Moreover, this effort can only be observed by conservation authorities at significant cost. Outcomes conditional on effort have a random environmental component that motivates opportunistic behaviour among managers and moral hazard.

Compensation to conservation managers must be adequate to reflect these uncertainties. Risk averse managers must be paid enough to offset the chance that resources being conserved may eventually have low social value. A fixed component of compensation must also compensate managers for the chance that random environmental circumstances may adversely offset conservation efforts resulting in low eventual rewards. Conservation managers cannot be paid only a fixed reward, since incentives to provide effort are then eliminated as in standard principal-agent problems (Moyle, 1998; Milgrom and Roberts, 1992).

Inevitably, regulations and contracting will require monitoring by conservation agencies. Loose and changing conservation objectives can, at best, be formalised in an incomplete contract or by provisional regulations. Then, given selfishness, individual managers will have incentives to shirk and landowners will have incentives to avoid regulations. Monitoring the achievement of conservation objectives can foster favourable 'reputation' effects if management contracts are made subject to renewal or if it is made clear that regulations can potentially be more intensively applied. Penalties can be imposed for non-achievement of specific contract objectives while poor performance with respect to noncontractible quality objectives or unregulated biodiversity characteristics can be dealt with either by non-renewal of contract (or threat of non-renewal) or by intensified future regulations (or threat of such).

That monitoring is expensive is a reason for seeking decentralised control. Inexpensive monitoring involves observation primarily when contracts are awarded. A simple private monitoring scheme then might involve awarding leasehold rights to own or manage land with lease renewal being subject to achievement of biodiversity objectives. This has not been how leasehold

\footnotetext{
${ }^{4}$ Aretino et al. (2001) are confused on this point and seem to misunderstand the Coase theorem. They favour 'impacter pays' property right assignments using arguments that mix 'efficiency' and 'equity' objectives.
} 
agriculture in Australia has been managed. Australian leases have been very longterm with emphasis on destroying rather than conserving biodiversity by encouraging clearing. Recently, sustainable development criteria have been inserted into lease contracts. This can be taken further by employing shorter leases and still more specific biodiversity objectives.

When requisite monitoring costs are very high and incentive design issues complex, there re-emerges a case for dedicated public conservation. Private ownership with regulation and public ownership with incentive contracts are then inferior to public ownership with public management.

\section{Coordination issues and contracting}

Coordination issues create specific contracting difficulties for two reasons: there are relations between distinct biodiversity types at a given location and between conservation activities at different locations.

Species interrelationships can be so complex and crucial for ecosystem stability that ecologists often advocate conservation of habitats, ecosystems or 'communities' rather than sets of species (Meffe et al., 1997:chapter 8). This can create regulatory and contracting difficulties. So-called keystone species can have a disproportionate impact, relative to their abundance, on community structure. These species may not comprise charismatic fauna but might, for example, include mycorrhizal fungi that enhance a plant's ability to extract nutriments from soils. Such species require specific management effort of identifying and maintaining symbiotic mutualisms. Other management issues include problems with invasive species and the possible overabundance of certain species populations and consequent arguments for culling. Managing complex ecosystems can require inputs of training and experience in conservation biology that are difficult to elicit using a simple incentive contract. With enough complexity, dedicated public sector management can again become appropriate.

In addition, conservation is undertaken in physical space as emphasised in the biogeography theory of Harris (1987). Extinction rates are higher in small 'disconnected' islands of habitat so connected habitat corridors need to be maintained if extinction risks are to be minimised. In addition, migration of species may call for coordinated conservation of habitat in different locations (see Clarke, 2003). Private markets and regulations are poor ways of achieving coordination so public sector management may be optimal for geographic reasons.

Non-contractible quality issues

Incentive contracts seek cost efficiency and innovation. With incomplete contracts, however, cost cutting can result in non-contractible biodiversity quality losses. Schleifer (1998) sees four reasons for avoiding incentive contracts with private managers:

(i) When cost reductions lead to significant non-contractible quality deterioration. With respect to biodiversity conservation, cost savings can be 
realised by sacrificing difficult-to-define aspects of environmental quality such as economising on research or on the conservation of non-charismatic biodiversity. In this case, the public sector can become a more efficient provider because its employees are not motivated to employ such inefficient cost reductions.

(ii) When innovation is unimportant. An appropriately motivated private manager has incentives to improve biodiversity provision efficiency. For example, attractive, environmentally benign complement goods can be provided with a biodiversity experience or access costs to biodiversity reduced through improved roads. When there is limited scope for such innovation, adverse cost changes, as in (i), become more significant in contract design and the case for public provision strengthens.

(iii) When consumer choice is ineffective. Adverse quality effects of cost cutting are important when competition does not limit incentives to use them. Incentives to adversely cut costs are limited if consumers can substitute alternative resources. Consumer choices are also ineffective if biodiversity consumers are just too misinformed to make meaningful choices when a merit good argument can motivate public provision.

(iv) When reputation is unimportant in contract renewal. Opportunistic private manager actions are constrained by their desire for further contracts. If such reputation effects are relatively unimportant the case for public provision increases.

These points determine whether cost reductions have significant effects on non-contractible quality. An argument for public provision becomes stronger when stick or carrot monitoring or incentive contracts cannot feasibly address quality effects. Hart et al. (1997), for example, focus on tradeoffs between achieving cost efficiency and quality of services provided. This model, originally developed for prison management, is adapted to the case of biodiversity provision in an appendix provided in an expanded version of this paper (available from the author). The main idea is that public employees or private contractors can invest time in improving service quality or in reducing service costs with cost reductions reducing quality. Neither improving service quality nor reducing costs is ex ante contractible but both types of innovation require approval from the owner of the biodiversity. If the public sector is the owner, it shares in gains accruing from cost reductions or quality improvements so that not all gains from cost-reducing effort accrue to its employees. Employee gains are also limited by the fact that employees can be replaced. However, if the provider is a private contractor they do not need public approval for cutting costs. They only need to negotiate with government to secure a better price on quality improvements since government values biodiversity service. Private contractors have stronger incentives to cut costs and improve quality but cost cutting will be socially excessive since effects on quality are ignored. 
Generally, the case for outsourcing biodiversity conservation is seen to be stronger when quality-reducing cost reductions can be controlled through contract or competition.

\section{Conclusions and Final Remarks}

With non-attenuated property rights and without competitive distortions, private markets ensure efficient biodiversity conservation given complementarities in either production or consumption. The obstacles to private provision are neither externalities nor nonrivalrousness. Externalities can be internalised using economic instruments such as taxes while nonrivalrousness can be catered for in club good structures where, if necessary, subsidies are provided if externalities arise.

Non-attenuated property rights, however, characterise idealised, utopian situations so that biodiversity conservation has traditionally been pursued on publicly-owned and publicly-managed land. Indeed, the case for public involvement in conservation remains strong on the basis of the present analysis with the public reserve system being an important component of national conservation efforts. This role is vital when resource use is non-excludable, when costs of contracting conservation effort, including monitoring, are high and when agency costs are a particular problem.

The completeness and excludability of property rights remain issues limiting the private sector's ability to deliver efficiency. These limitations do not arise if biodiversity resources have a high known use value as in farming, zoos, captive breeding programs or flora and fauna reserves with high demand and low transaction costs of pricing. Then conservation is easily realised in private markets. However, it is in the important case of low use values and high non-use values that incompleteness or non-excludability problems drive a case for public provision.

There are reasons for conserving biodiversity on private as well as public land. Such activity increases the scope of conservation effort and hence its effectiveness. The major difficulty in involving the private sector can be seen to stem not from externalities or nonrivalry but rather from difficulties in designing appropriate regulations or contracting biodiversity management.

\section{References}

Aretino, B., P. Holland, A. Matysek and D. Peterson (2001), Cost Sharing for Biodiversity Conservation: A Conceptual Approach, Productivity Commission Staff Research Paper, AusInfo, Canberra.

Clark, C. (1976), Mathematical Bioeconomics, Wiley-Interscience, New York.

Clarke, H. (1997), 'Australian Tourism Industry Policy: A New View', Tourism Economics 3(4):361-378. 
Clarke, H. (1999), 'International Species Protection Agreements: Migratory Shorebirds in the East-Asian Australasian Flyway’, The Stilt 35(October):18-24.

Clarke, H. (2000a), 'Aesthetics, Economics and Conservation of the Endangered OrangeBellied Parrot', Agenda 7(2):153-166.

Clarke, H. (2000b), 'Bird Migrations and the International Economics of Species Conservation', Australian Journal of Agricultural and Resource Economics 44(1):31-54.

Clarke, H. (2003), 'International Biodiversity Conservation Agreements', Natural Resource Modeling, forthcoming.

Clarke, H. and W.J. Reed, (1990), 'Land Development and Wilderness Conservation Policies Under Uncertainty: A Synthesis', Natural Resource Modeling 4(1):11-37.

Clarke, H., W. Reed and R. Shrestha, (1993), 'Optimal Enforcement of Property Rights on a Forest Subject to Encroachment', Resource and Energy Economics 15(2):271-293.

Earth Sanctuaries Limited, (1999), Annual Report 1999, Lane Print Group.

Environment Australia (2001), National Strategy for the Conservation of Australia's Biodiversity, AGPS, Canberra.

Gaston, K. (1996) (ed.), Biodiversity: A Biology of Numbers and Difference, Blackwell.

Harris, L. (1987), The Fragmented Forest, University of Chicago Press, Chicago.

Hart, O., A. Shleifer and R. Vishny, (1997), 'The Proper Scope of Government: Theory and an Application to Prisons', Quarterly Journal of Economics 112(4):1127-1162.

Henry, C. (1974), 'Option Values in the Economics of Irreplaceable Assets', The Review of Economic Studies Symposium:89-104.

Industry Commission, (1998), A Full Repairing Lease, Report No. 60, AGPS, Canberra, 27 January.

Kriström, B. and P. Riera, (1996), 'Is the Income Elasticity of Environmental Improvements Less Than One?', Environmental and Resource Economics 7:45-55.

Laffont, J. (1988), Fundamentals of Public Economics, The MIT Press, Cambridge.

Lovelock, J. (1988), The Ages of Gaia, New York, Norton.

Meffe, G., C. Carroll and Contributors (1997), Principles of Conservation Biology, Sinauer Associates, Sunderland.

Milgrom P. and J. Roberts, (1992), Economics, Organization and Management, Prentice Hall, New Jersey.

Moyle, B. (1998), 'Species Conservation and the Principal-Agent Problem', Ecological Economics 26:313-320.

Productivity Commission, (2001), Creating Markets for Biodiversity: A Case Study of Earth Sanctuaries Ltd, Workshop Paper, OECD International Workshop, Paris, January. 
Sandler, T. and L. Tschirhart, (1980), 'The Economic Theory of Clubs: An Evaluative Survey', Journal of Economic Literature 18(4):1481-1521.

Shleifer, A. (1998), 'State Versus Private Ownership', Journal of Economic Perspectives 12(4):133-150.

Spellerberg, I. and S. Hardes, (1992), Biological Conservation, Cambridge University Press, Cambridge.

Wilson, E. (1984), Biophilia, Cambridge, Harvard University Press.

The author is grateful to two anonymous referees for their careful review of my arguments and for their helpful suggestions. Thanks also to Lee Smith and Franco Papandrea for editorial assistance. This is a revised version of a paper presented to the Industry Economics Conference, Melbourne Business School, June 2001. 